\title{
Crystal and Molecular Structure of DL-Serine Hydrochloride Studied by X-Ray Diffraction, Low-Temperature Fourier Transform Infrared Spectroscopy and DFT(B3LYP) Calculations
}

\author{
S. Jarmelo, ${ }^{*},{ }^{\dagger}$ I. Reva, ${ }^{\dagger}$ M. Rozenberg, ${ }^{\ddagger}$ M. Ramos Silva, ${ }^{\S}$ A. M. Matos Beja, ${ }^{\S}$ and R. Fausto ${ }^{\dagger}$ \\ Department of Chemistry, University of Coimbra, Coimbra 3004-535, Portugal, Department of Inorganic and \\ Analytical Chemistry, The Hebrew University of Jerusalem, Givat Ram, Jerusalem 91904, Israel, and \\ Department of Physics, University of Coimbra, Coimbra 3004-536, Portugal
}

Received: December 7, 2007; Revised Manuscript Received: February 25, 2008

\begin{abstract}
The structure of DL-serine $\cdot \mathrm{HCl}$ was studied by three complementary techniques. Experimental Fourier transform infrared (FT-IR) spectra of pure $\mathrm{NH} / \mathrm{OH}$ polycrystalline DL-serine $\cdot \mathrm{HCl}\left[\mathrm{HO}-\mathrm{CH}_{2}-\mathrm{CH}\left(\mathrm{NH}_{3}{ }^{+}\right)-\mathrm{COOH} \cdot \mathrm{Cl}^{-}\right]$and the respective deuterated derivatives $\left[\mathrm{ND} / \mathrm{OD}_{\text {Alcohol/Acid }}(<10 \%\right.$ and ca. $\left.60 \% \mathrm{D})\right]$ were recorded in the region $4000-400 \mathrm{~cm}^{-1}$ in the temperature range $300-10 \mathrm{~K}$ and interpreted. The assignments were confirmed by comparison with the vibrational spectra of crystalline DL- and L-serine zwitterions $\left[\mathrm{HO}-\mathrm{CH}_{2}-\mathrm{CH}\left(\mathrm{NH}_{3}{ }^{+}\right)-\mathrm{COO}^{-}\right]$. Further insight into the structure of the title compound was provided by theoretical DFT(B3LYP)/6-311++G(d,p) calculations of the infrared spectra and energies of 13 different conformers. Potential energy distributions resulting from normal coordinate analysis were calculated for the most stable conformer (I) in its hydrogenated and deuterated modification. Frequencies of several vibrational modes were used in the estimation of enthalpies of individual $\mathrm{H}$-bonds present in the crystal, using empirical correlations between enthalpy and the frequency shift that occurs as a result of the establishment of the $\mathrm{H}$-bonds. X-ray crystallography data for DL-serine $\cdot \mathrm{HCl}$ were recorded for the first time and, together with the experimental vibrational spectra and the theoretical calculations, allowed a detailed characterization of its molecular structure.
\end{abstract}

\section{Introduction}

It is well-known that amino acids in the gaseous phase and isolated in gas noble matrices adopt the nonionic form $\left(\mathrm{H}_{2} \mathrm{~N}-\mathrm{CHR}-\mathrm{COOH}\right),{ }^{1,2}$ while in the neat solid state they exist in the zwitterionic form $\left(\mathrm{H}_{3} \mathrm{~N}^{+}-\mathrm{CHR}-\mathrm{COO}^{-}\right) .{ }^{3-5}$ In solutions, amino acids appear as ionic species whose nature is determined by the $\mathrm{pH}$ and by the specific structure of the particular amino acid that determines its isoelectric point. At high $\mathrm{pH}$, amino acids appear predominantly as anionic species $\left(\mathrm{H}_{2} \mathrm{~N}-\mathrm{CHR}-\mathrm{COO}^{-}\right)$, while at low $\mathrm{pH}$ they are prone to adopt a cationic form $\left(\mathrm{H}_{3} \mathrm{~N}^{+}-\mathrm{CHR}-\mathrm{COOH}\right) .{ }^{6}$ The latter situation can occur, for example, for amino acid hydrochlorides. As the subject of the present study, we have selected serine hydrochloride since we have previously studied this amino acid under other experimental conditions, such as monomers isolated in cryogenic inert matrices ${ }^{2}$ and in its neat crystalline states. ${ }^{4,5}$

In our previous studies on serine in the solid crystalline state, the crystals were constituted by different enantiomeric forms: racemic mixture DL-serine (DL-Ser) ${ }^{4}$ and enantiomerically pure L-serine (L-Ser) crystals. ${ }^{5}$ In those studies, we used lowtemperature Fourier transform infrared (FT-IR) spectroscopy and isotopic dilution techniques to investigate the crystalline H-bonding networks. The general approach used was formulated recently by Rozenberg et al. ${ }^{7-11}$ These previous results unequivocally demonstrated the existence of nonnegligible H-bonding disorder in some crystalline amino acids, ${ }^{8}$ which cannot be determined using standard structural methods (e.g., X-ray and neutron diffraction). Indeed, very often, the number of hydrogen bond contacts found by IR spectroscopy

\footnotetext{
* Corresponding author. E-mail:sjarmelo@qui.uc.pt.

$\dagger$ Department of Chemistry, University of Coimbra.

\$ The Hebrew University of Jerusalem.

$\S$ Department of Physics, University of Coimbra.
}

is larger than that obtained by structural methods, because of the higher sensitivity of the former method to short-range interactions as compared with the long-range periodic order seen by the latter techniques. ${ }^{12-14}$ This fact further reinforces the relevance of spectroscopic methods to investigate hydrogen bonding characteristics in the solid phases. The present study takes advantage of the complementary nature of the FT-IR spectroscopy/isotopic dilution method and X-ray diffraction in the investigation of the structural properties of serine in its acid form:DL-serine $\cdot \mathrm{HCl}\left[\mathrm{DL}-\mathrm{Ser} \cdot \mathrm{HCl} ; \mathrm{HO}-\mathrm{CH}_{2}-\mathrm{CH}\left(\mathrm{NH}_{3}{ }^{+}\right)-\mathrm{COOH} \cdot\right.$ $\mathrm{Cl}^{-}$.

Besides the studies undertaken in the solid state, theoretical [DFT(B3LYP)/6-311++G(d,p)] structural and vibrational studies on the isolated cationic form of serine followed by normal coordinate analysis calculations were also performed in order to help interpret the experimental data. To the best of our knowledge, only two studies have been performed previously on this species. ${ }^{15,16}$ Chakraborty and Manogaran ${ }^{15}$ studied the transferability of scale factors from glycine hydrochloride and ethanol to serine hydrochloride in an attempt to interpret the infrared spectra of serine in acidic solution. Noguera et al. ${ }^{16}$ studied theoretically, among other aminoacids, the structures of neutral and protonated serine. For the latter species they reported only a limited number of conformers (six).

\section{Materials and Methods}

Computational Details. DL-Ser in the cationic form has four conformationally relevant dihedral angles [they correspond to the single bonds in the following simplified formula: $\mathrm{HO}-\mathrm{CH}_{2}-\mathrm{CH}\left(\mathrm{NH}_{3}{ }^{+}\right)-\mathrm{C}(=\mathrm{O})-\mathrm{OH}$, which can result in 36 different conformations. Exploration of all possible forms, using high-level theoretical methods, will be computationally very expensive. Hence, a preliminary conformational search on the potential energy surface (PES) was carried out at the semiem- 
pirical PM3 level, using a stochastic approach based on modification of the four selected torsion angles. ${ }^{17}$ The structures resulting from the preliminary conformational search were used as starting geometries and optimized at a higher level, using the density functional theory (DFT) approach. These calculations revealed the existence of 13 conformers. The theoretical calculations were performed with the Gaussian 98 program package. ${ }^{18}$

The DFT calculations were performed with the $6-311++\mathrm{G}(\mathrm{d}, \mathrm{p})$ basis set ${ }^{19}$ and the three-parameter density functional, abbreviated as B3LYP, which includes the Becke's gradient exchange correction $^{20}$ and the Lee-Yang-Parr correlation functional. ${ }^{21}$ All the structures were subjected to full geometry optimization, having both the molecular charge and multiplicity set to 1 . Optimizations were followed by frequency calculations, performed at the same level of theory. The nature of the obtained stationary points was characterized by inspection of the corresponding Hessian matrices. The DFT(B3LYP)/6-311++G(d,p) harmonic frequencies were scaled using a single scaling factor of $0.978 .^{2}$

The most stable conformer of DL-Ser in a cationic form, found by DFT calculations, was reoptimized at the $a b$ initio $\mathrm{MP}^{22}$ level of theory, and the respective IR spectrum was calculated using the same basis set.

In this paper, the structural parameters "bond distance" and "bond angle" are designated by the letter $d$ and the symbol $\angle$, respectively.

Experimental Details. The acid salt of DL-Ser with natural isotopic content was prepared from commercial DL-Ser (Sigma) by adding an excess of concentrated $\mathrm{HCl}$ to the solid amino acid, the remaining solvent being evaporated later. The deuterated samples were obtained from DL-Ser $\cdot \mathrm{HCl}$ by exchange with $\mathrm{D}_{2} \mathrm{O}$ (Aldrich) in recirculating cyclohexane at $81^{\circ} \mathrm{C}$ as described elsewhere. ${ }^{23}$ Three types of isotopic mixtures were studied: pure $\mathrm{NH} / \mathrm{OH}, 10 \% \mathrm{ND} / \mathrm{OD}$, and ca. $60 \% \mathrm{ND} / \mathrm{OD}$.

The studied compound was suspended in a $\operatorname{KBr}(1: 200)$ pellet, attached to the coldfinger of an APD Cryogenics closed-cycle helium refrigeration system with a DE-202A expander. The temperature $(300-10 \mathrm{~K})$ was measured directly at the sample holder by a silicon diode temperature sensor connected to a Scientific Instruments temperature controller (model 9650) and was stabilized to ca. $\pm 0.2 \mathrm{~K}$ during registration of the spectra. Infrared spectra of the pellets were recorded with a Mattson Infinity 60AR series FT-IR spectrometer, with spectral resolution of $1 \mathrm{~cm}^{-1}$. The temperature-induced spectral changes observed for all substances were found to be reversible and highly reproducible.

X-ray data were collected on a Bruker APEX II-CCD diffractometer, using a transparent plate-shaped crystal with dimensions $0.57 \times 0.24 \times 0.12 \mathrm{~mm}^{3}$ inserted in a sealed glass capillary. The crystallographic structure was solved by direct methods using SHELXS-97. Refinements were carried out with the SHELXL-97 package. All refinements were made by fullmatrix least-squares on $\mathrm{F}^{2}$ with anisotropic displacement parameters for all non-hydrogen atoms.

\section{Results and Discussion}

In our previous studies on DL- and L-Ser, ${ }^{4,5}$ the interpretation of the experimental vibrational spectra was aided by the already existing structural data on the crystals of these molecules. ${ }^{24,25}$ In the case of DL-Ser hydrochloride, such structural information, according to the best of our knowledge, is not available. Therefore, this essential information was obtained in the present study.

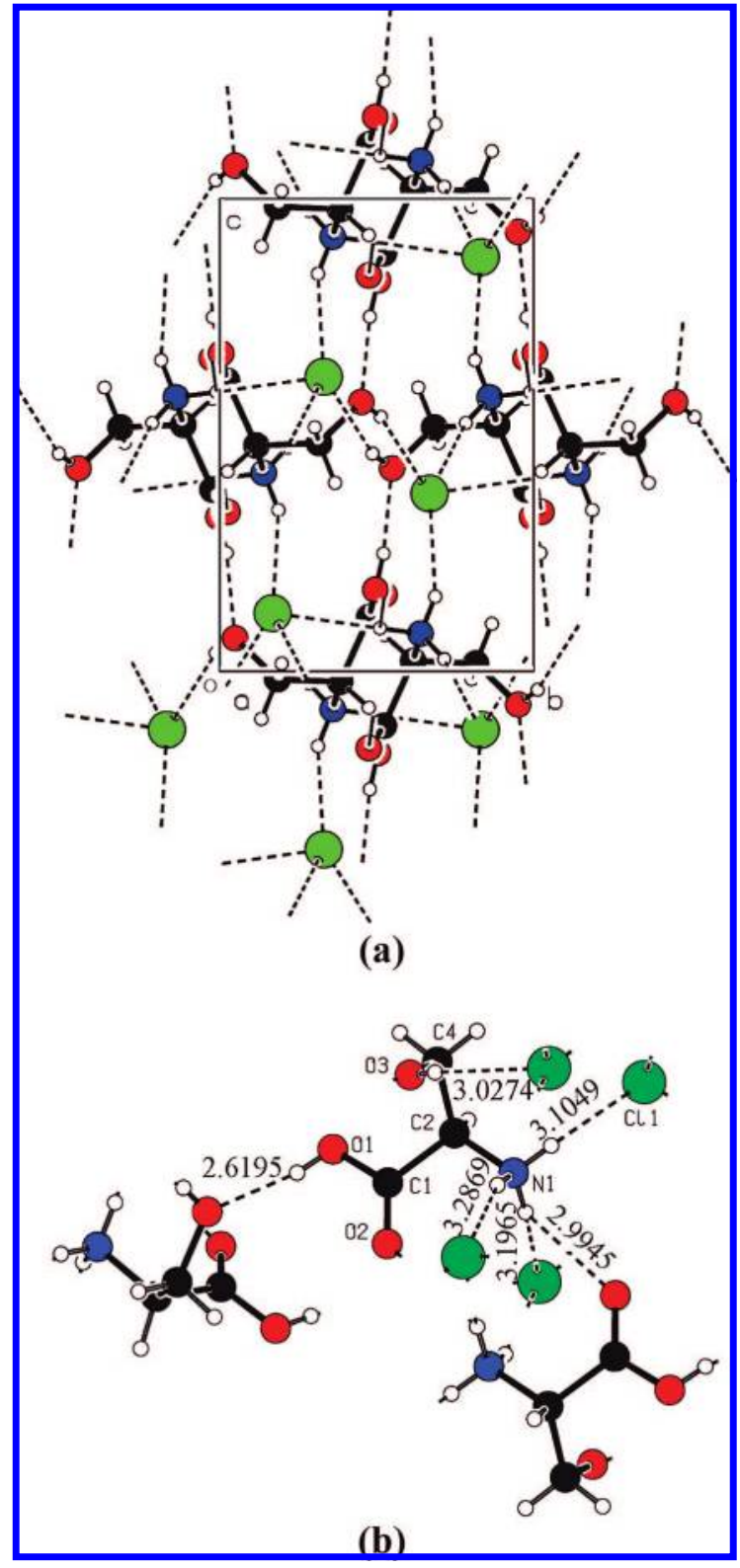

Figure 1. Crystalline structure of $\mathrm{DL}-\mathrm{Ser} \cdot \mathrm{HCl}$ determined by $\mathrm{X}$-ray diffraction: (a) Packing diagram viewed along the $a$ axis. Hydrogen bonds are depicted as dashed lines. (b) Detail of the hydrogen bond network showing one of the $\mathrm{D}$ enantiomers and its nearest neighbours. Numbers correspond to donor-acceptor distances in angstroms.

The DL-Ser $\cdot \mathrm{HCl}$ crystal was found to be monoclinic (space group: $P 2_{1} / c$ ), with one independent molecule in the unit cell, whose volume is $624.89(3) \AA^{3}$ and lattice constants are $a=9.3040(2), b=6.6665(2)$, and $c=11.7804(3) \AA$, and $\beta=121.216(2)^{\circ}$, at ambient conditions. The $\mathrm{D}-$ and $\mathrm{L}^{-}$ components assume the same conformation in the crystal, being mirror images of each other. In the L-component, the $\mathrm{N}-\mathrm{C}_{\alpha}-\mathrm{C}_{\beta}-$ $\mathrm{O}$ torsional angle is $-64.37^{\circ}$, and the $\mathrm{C}-\mathrm{C}_{\alpha}-\mathrm{C}_{\beta}-\mathrm{O}$ angle is $56.67^{\circ}$. As expected, the carboxylic group is protonated, as shown by the $\mathrm{CO}$ distances: $1.31 \AA$ for $\mathrm{C}-\mathrm{O}_{\text {Acid }}$ and $1.20 \AA$ for $\mathrm{C}=\mathrm{O}$. There is a complex three-dimensional hydrogen bonding network. The cations exhaust their capacity as hydrogen donors, and the chloride anions accept four hydrogen atoms from distinct cations (Figure 1 and Table 1).

The hydrophilic side chain of serine endows an additional $-\mathrm{OH}$ group, which, like the ammonium group $\left(-\mathrm{NH}_{3}{ }^{+}\right)$forms hydrogen bonds in crystals. However, unlike the ammonium 
TABLE 1: X-ray Data on the Hydrogen-Bonding Related Geometric Parameters in the Crystal of DL-Ser $\cdot \mathrm{HCl}$

\begin{tabular}{ccccc}
\hline donor $-\mathrm{H} \cdots$ acceptor & donor $-\mathrm{H}(\AA)$ & $\mathrm{H} \cdots$ acceptor $(\AA)$ & donor $\cdots$ acceptor $(\AA)$ & donor $-\mathrm{H} \cdots$ acceptor $\left({ }^{\circ}\right)$ \\
\hline $\mathrm{O}-\mathrm{H}_{\mathrm{C}} \cdots \mathrm{O}_{\mathrm{A}}$ & $0.8004^{a}$ & 1.8284 & 2.6195 & 169.52 \\
$\mathrm{O}-\mathrm{H}_{\mathrm{A}} \cdots \mathrm{Cl}^{-}$ & $0.6525^{a}$ & 2.3958 & 3.0274 & 163.60 \\
$\mathrm{~N}-\mathrm{H}(1) \cdots \mathrm{Cl}^{-}$ & 0.8544 & 2.3195 & 3.1049 & 152.96 \\
$\mathrm{~N}-\mathrm{H}(2) \cdots \mathrm{Cl}^{-}$ & 0.8768 & 2.4433 & 3.2869 & 161.59 \\
$\mathrm{~N}-\mathrm{H}(3) \cdots \mathrm{Cl}^{-}$ & 0.9332 & 2.3045 & 3.1965 & 159.77 \\
$\mathrm{~N}-\mathrm{H}(3) \cdots \mathrm{O}=$ & 0.9332 & 2.5384 & 2.9945 & 110.41 \\
$\mathrm{C}_{\alpha}-\mathrm{H} \cdots \mathrm{O}_{\mathrm{C}}$ & 0.9981 & 2.5811 & 3.4163 & 141.15
\end{tabular}

${ }^{a}$ Distances shorter than usual. The positions of hydrogen atoms were determined by difference Fourier synthesis $(R=0.035)$ and refined free of constraints. As it is well-known, the weak dispersion of X-rays by a single electron makes it difficult to accurately determine the hydrogen positions.

TABLE 2: Calculated DFT(B3LYP)/6-311++G(d,p) Structural and Energetic Parameters of the L-Form of Cationic Serine $\left[\mathrm{HO}-\mathrm{CH}_{2}-\mathrm{CH}\left(\mathrm{NH}_{3}{ }^{+}\right)-\mathrm{COOH}\right]$ and Experimental X-ray Structural Parameters of the L-Form in the Crystal of DL-Ser $\cdot \mathrm{HCl}$

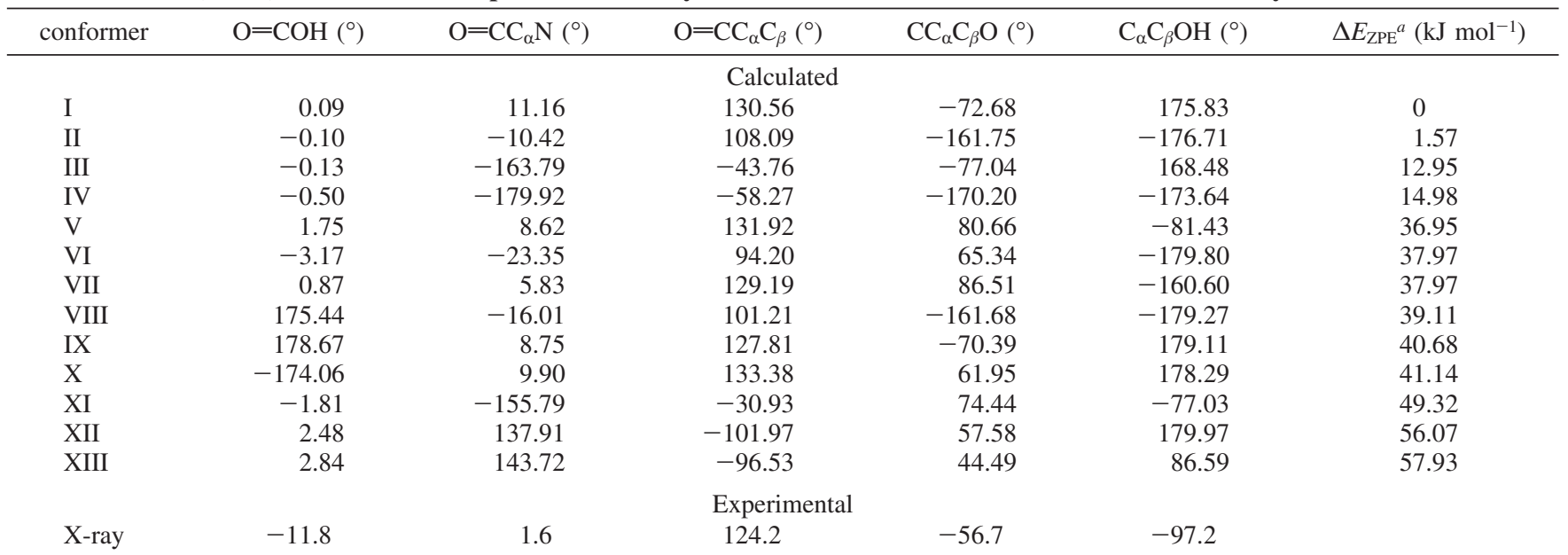

${ }^{a}$ The DFT(B3LYP)/6-311++G(d,p) calculated energy for conformer I is $-1048438.743 \mathrm{~kJ} \mathrm{~mol}^{-1}$ (nonscaled zero-point energy is included) and it was chosen as the relative zero level.

group, the side-chain $-\mathrm{OH}$ group has great flexibility and may lead to different patterns of the hydrogen-bonded networks. For example, in crystals of glycine hydrochloride, ${ }^{26}$ the molecules are organized in cyclic dimers typical of carboxylic acids. On the contrary, the present X-ray data reveal that this type of dimer is not characteristic of DL-Ser $\cdot \mathrm{HCl}$ crystals, most likely on account of an increased number of $\mathrm{H}$-bonds to the chlorine atom and the flexibility of the side-chain $-\mathrm{OH}$ group.

Along with strong intermolecular hydrogen bonds present in the crystal (Figure 1 and Table 1), the experimental X-ray geometry suggests that weak intramolecular H-bonds may also be formed in protonated serine. Indeed, two hydrogen atoms of the protonated amino group are located in close vicinity of the carbonyl oxygen. The experimental $=\mathrm{O} \cdots \mathrm{H}$ distances are equal to 2.60 and $2.54 \AA$.

Since the experimental X-ray structure of $\mathrm{DL}-\mathrm{Ser} \cdot \mathrm{HCl}$ revealed that the main building unit of the crystals is not the typical dimer, but rather resembles monomeric molecules, it would be interesting to theoretically characterize the monomeric structure of the serine cation. The cation represents a conformationally flexible entity due to different possible orientations of the $-\mathrm{COOH}$ and $-\mathrm{CH}_{2} \mathrm{OH}$ groups with respect to the $-\mathrm{NH}_{3}{ }^{+}$ group. On the monomeric level, the D- and L-Ser will produce the same set of conformers; therefore all calculations were carried out on the L-form. Thirteen conformers were localized on its PES (Figures S1 and S2; suffix "S" in the names of figures and tables stands for Supporting Information). The conformationally relevant parameters of these structures along with their relative energies are collected in Table 2 and compared with the structural parameters obtained by X-ray. A more extended version of Table 2, with all the structural parameters (i.e., bond lengths, bond angles and dihedrals) of the thirteen conformers and the respective dipole moments and relative energies, is presented in Table S1. It is interesting to note that the four lowest energy conformers of the protonated serine found in the present work match well with the four lowest energy forms of this species found previously. ${ }^{16}$ The conformational search performed by Noguera et al. started from the well-studied conformations of glycine. Using this approach, these authors found six minima for protonated serine; however, they pointed out that such an approach may fail in finding some conformational minima. Indeed, in the present study, exploration of the entire conformational space by allowing all possible combinations of single-bond rotamers revealed the existence of seven additional minima, but no new low-energy minima could be found in the $0-30 \mathrm{~kJ} \mathrm{~mol}^{-1}$ range.

The structural results obtained for the calculated conformer I are in the best agreement with the X-ray results for the crystal. Consequently, the calculated geometric and, in particular, vibrational parameters of conformer I will be used, when required, in the interpretation of the experimental spectroscopic results. The definition of the internal symmetry coordinates used in the normal coordinates analysis is given in Table S2. The theoretical frequencies, infrared intensities, and the potential energy distribution (PED) of the corresponding normal modes for the non-deuterated $\left[\mathrm{HO}-\mathrm{CH}_{2}-\mathrm{CH}\left(\mathrm{NH}_{3}{ }^{+}\right)-\mathrm{COOH}\right]$ and deuterated [DO- $\left.\mathrm{CH}_{2}-\mathrm{CH}\left(\mathrm{ND}_{3}{ }^{+}\right)-\mathrm{COOD}\right]$ species are collected in Tables S3 and S4, respectively.

In order to check the agreement between the calculated and experimental spectra of the cationic form of serine, 
MP2/6-311++G(d,p) calculations on the most stable conformer (I) of this species were also performed (see Tables S1 and S5 for the structural and vibrational data, respectively). It was concluded that the calculated vibrational spectra at both levels of theory (DFT and MP2) are essentially equal. Thus, the calculated DFT results will be used in the interpretation of the experimental data.

The analysis of the FT-IR spectra will be divided into two regions: $4000-2000 \mathrm{~cm}^{-1}(\mathrm{XH}$ stretching region, $\mathrm{X}=\mathrm{N}, \mathrm{O}$, C) and 2000-400 $\mathrm{cm}^{-1}$ (fingerprint region). Each of them includes the vibrational results of crystals of $\mathrm{DL}-\mathrm{Ser} \cdot \mathrm{HCl}$ with natural isotopic abundance and isotopically doped samples $\left(\mathrm{NH} / \mathrm{OH}_{\mathrm{A} / \mathrm{C}}\right.$ in a D-bulk and $\mathrm{ND} / \mathrm{OD}_{\mathrm{A} / \mathrm{C}}$ in an $\mathrm{H}$-bulk; where the subscript A stands for alcohol, while the subscript $\mathrm{C}$ stands for carboxylic group). The observed frequencies and qualitative intensities are given in Table 3 together with the proposed assignments.

Of particular interest in this study are the temperature and isotopic shift effects on the $\mathrm{NH}$ and $\mathrm{OH}$ proton modes, which provide useful information both on the structure of DL-Ser $\cdot \mathrm{HCl}$ crystal and on its associated $\mathrm{H}$-bond energetics. Table 4 shows the observed frequencies and assignments for the bands corresponding to uncoupled $\mathrm{NH} / \mathrm{OH}_{\mathrm{A} / \mathrm{C}}$ and $\mathrm{ND} / \mathrm{OD}_{\mathrm{A} / \mathrm{C}}$ modes in isotopically diluted $\mathrm{DL}-\mathrm{Ser} \cdot \mathrm{HCl}$ crystals, which are associated with vibrations of individual bonds.

The frequencies of the proton vibrational modes of crystalline DL-Ser $\cdot \mathrm{HCl}$ have never been correlated with $\mathrm{H}$-bond energies. In nonisotopically doped crystalline $\mathrm{DL}-\mathrm{Ser} \cdot \mathrm{HCl}$, the proton stretching modes of ammonium group give rise to a very broad and extensively structured band, not allowing any direct identification of the features due to the individual $\mathrm{N}-\mathrm{H}$ stretching vibrations. On the other hand, in the partially isotopically labeled $\mathrm{DL}-\mathrm{Ser} \cdot \mathrm{HCl}$ crystals, such features could be easily identified. At deuterium doping concentrations less than $10 \%$, a minority of D-containing molecules is surrounded by an $\mathrm{H}$-bulk. Under these circumstances, the vibrational modes with dominant contribution from the deuterated fragments are free from both internal dynamic coupling, because of mass and/or symmetry restrictions, and coupling with neighboring hydrogen bonds. Furthermore, application of low temperature considerably enhances the power of the isotopic doping method in the study of hydrogen-bonding interactions in crystals, since, under these experimental conditions, thermal broadening is also minimized, ${ }^{27}$ and the intrinsic resolution of the IR bands considerably improves. Note that both the stretching and out-of-plane (wagging and torsional) vibrations of the groups taking part in $\mathrm{H}$-bonding as donors have been found to be very sensitive to the properties of the specific hydrogen bonds in which they are involved, ${ }^{13,14}$ and may be used as suitable probes of the hydrogen bonding interactions. This analysis will be described in detail in another section of the paper.

The Range 4000-2000 $\mathbf{c m}^{-1}$. The spectra of natural $(100 \% \mathrm{H})$ and isotopically doped $\left(\mathrm{NH} / \mathrm{OH}_{\mathrm{A} / \mathrm{C}}\right.$ in a D-bulk and $\mathrm{ND} / \mathrm{OD}_{\mathrm{A} / \mathrm{C}}$ in an $\mathrm{H}$-bulk) samples of DL-Ser $\cdot \mathrm{HCl}$ are shown in Figures 2-4. Additionally, the spectra of natural and isotopically doped samples of $\mathrm{DL}-\mathrm{Ser} \cdot \mathrm{HCl}$ at four different temperatures $(300,200,100$, and $10 \mathrm{~K})$ are shown in Figures S3-S5. The peak positions are denoted for the spectra at $10 \mathrm{~K}$.

Both neutral serine $\left[\mathrm{HO}-\mathrm{CH}_{2}-\mathrm{CH}\left(\mathrm{NH}_{2}\right)-\mathrm{COOH}\right]$ and its acid salt $\left[\mathrm{HO}-\mathrm{CH}_{2}-\mathrm{CH}\left(\mathrm{NH}_{3}{ }^{+}\right)-\mathrm{COOH} \cdot \mathrm{Cl}^{-}\right]$contain the $\mathrm{OH}$ alcohol and acid groups in their constitution. Thus, two features due to the stretching vibrations of these two $\mathrm{OH}$ groups should contribute to their IR spectra. On the other hand, in the IR spectra of both DL- and L-Ser crystals, where serine appears in a zwitterionic form $\left[\mathrm{HO}-\mathrm{CH}_{2}-\mathrm{CH}\left(\mathrm{NH}_{3}{ }^{+}\right)-\mathrm{COO}^{-}\right.$, just the spectral feature due to the $\mathrm{OH}$ alcohol stretching should appear.

For conformer $\mathbf{I}$ of the cationic form of serine, investigated at the DFT(B3LYP)/6-311++G(d,p) level of theory, $v \mathrm{OH}_{\mathrm{A}}$ is predicted to appear at higher wavenumbers than $v \mathrm{OH}_{\mathrm{C}}(3751$ versus $3639 \mathrm{~cm}^{-1}$; Table S3). In the crystal of DL-Ser $\cdot \mathrm{HCl}$, $\mathrm{X}$-ray results show that both hydroxyl groups are involved in intermolecular $\mathrm{H}$-bonds acting as proton donor groups $\left[\mathrm{O}-\mathrm{H}_{\mathrm{C}} \cdots \mathrm{O}_{\mathrm{A}}: d\left(\mathrm{O}_{\mathrm{C}} \cdots \mathrm{O}_{\mathrm{A}}\right)=2.6195 \AA, \angle\left(\mathrm{O}-\mathrm{H}_{\mathrm{C}} \cdots \mathrm{O}_{\mathrm{A}}\right)=\right.$ $169.52^{\circ} ; \quad \mathrm{O}-\mathrm{H}_{\mathrm{A}} \cdots \mathrm{Cl}^{-}: \quad d\left(\mathrm{O}_{\mathrm{A}} \cdots \mathrm{Cl}^{-}\right)=3.0274 \AA$ $\left.\angle\left(\mathrm{O}-\mathrm{H}_{\mathrm{A}} \cdots \mathrm{Cl}^{-}\right)=163.60^{\circ}\right]$. Thus, in the crystal, the corresponding frequencies should undergo a pronounced red shift relative to the frequencies calculated for the monomer. And, indeed, the observed $\mathrm{OH}_{\mathrm{A}}$ stretching mode gives rise to the features in the $3550-3250 \mathrm{~cm}^{-1}$ range, whereas the $\mathrm{OH}_{\mathrm{C}}$ stretching mode contributes to the very broad and structured absorption located between 3150 and ca. $2850 \mathrm{~cm}^{-1}$.

At room temperature, the band due to the $\mathrm{OH}_{\mathrm{A}}$ stretching mode appears as a broad feature centered at about $3350 \mathrm{~cm}^{-1}$ (Figure 2a, dashed line). As expected, this band becomes progressively narrower and more intense upon cooling as a result of the depopulation of thermal phonons. At the lowest temperature attainable in our experiments $(10 \mathrm{~K})$, the $\mathrm{OH}_{\mathrm{A}}$ stretching vibration corresponds to the band with the main maximum at $3341 / 3339 \mathrm{~cm}^{-1}$ (Figure 2a, solid line; Table 3).

It is very interesting to compare the relative position of the band ascribed to $\nu \mathrm{OH}_{\mathrm{A}}$ in the crystals of DL-, L-Ser and DL-Ser $\cdot \mathrm{HCl}$. In the crystal of $\mathrm{L}-\mathrm{Ser}$, the $\mathrm{O}-\mathrm{H}_{\mathrm{A}} \cdots \mathrm{O}_{\mathrm{A}}$ intermolecular $\mathrm{H}$-bonds were found to be relatively weak, the H-bond distance being $2.9181 \AA .{ }^{25}$ On the other hand, in the crystal of DL-Ser, the alcohol group is H-bonded to the carboxylic group of a neighbor molecule. ${ }^{24,28}$ This $\mathrm{O}-\mathrm{H}_{\mathrm{A}} \cdots \mathrm{O}_{\mathrm{C}}$ intermolecular $\mathrm{H}$-bond is considerably stronger than the $\mathrm{O}-\mathrm{H}_{\mathrm{A}} \cdots \mathrm{O}_{\mathrm{A}} \mathrm{H}$-bond in L-Ser crystal, as reflected by the corresponding H-bond distance: $2.671 \AA$ A. ${ }^{28}$ Finally, the present X-ray data revealed that, for the crystal of DL-Ser $\cdot \mathrm{HCl}$, the $\mathrm{O}-\mathrm{H}_{\mathrm{A}}$ group establishes an intermolecular $\mathrm{H}$-bond with a chlorine ion, $\mathrm{O}-\mathrm{H}_{\mathrm{A}} \cdots \mathrm{Cl}^{-}$. This interaction is characterized by a distance of $3.0274 \AA$ and an angle of $163.60^{\circ}$, which is close to the linearity. For such a voluminous acceptor as the chlorine atom, the observed $\mathrm{H}$-bond distance corresponds to a moderately strong interaction, situated between those of the DL- and L-Ser, where an oxygen atom is acting as a proton acceptor. Accordingly, the position of the $\nu \mathrm{OH}_{\mathrm{A}}$ infrared absorption band in the three crystals clearly reflects the different packing appearing in the inverse order relative to the strength of the $\mathrm{H}$-bond. The highest frequencies are observed in the spectrum of L-Ser $(3529,3501$, and 3465 $\mathrm{cm}^{-1}$ ), ${ }^{5}$ followed by DL-Ser $\cdot \mathrm{HCl}\left[3341 / 3339 \mathrm{~cm}^{-1}\right.$ (Figure 2a and Table 3)], and, finally, in the spectrum of DL-Ser (ca. 2900 $\left.\mathrm{cm}^{-1}\right){ }^{4}$

The bands in the IR spectrum of the crystal of DL-Ser $\cdot \mathrm{HCl}$ in the range $3255-2735 \mathrm{~cm}^{-1}$ are assigned to the $\nu \mathrm{NH}_{3}{ }^{+}$and $v \mathrm{CH}$ vibrations (Table 3 ). The $v \mathrm{CH}$ frequencies were calculated for the monomer in the range $3050-2950 \mathrm{~cm}^{-1}$ (Table S3). As expected, the $v \mathrm{CH}$ vibrations do not shift much in the IR spectrum of the crystal, since they are not involved in the H-bonding (Table 3).

The DFT(B3LYP)/6-311++G(d,p) calculations for the monomer predict the stretching modes of $-\mathrm{NH}_{3}{ }^{+}$group in the range $3400-3200 \mathrm{~cm}^{-1}$ (Table S3). In the crystal of DL-Ser $\cdot \mathrm{HCl}$, the ammonium group, like the $-\mathrm{OH}_{\mathrm{A}}$ group, is also involved in different intermolecular $\mathrm{H}$-bonds, acting as a protondonor $\left[\mathrm{N}-\mathrm{H}(1) \cdots \mathrm{Cl}^{-}, \mathrm{N}-\mathrm{H}(2) \cdots \mathrm{Cl}^{-}\right.$, and $\mathrm{N}-\mathrm{H}(3) \cdots \mathrm{Cl}^{-}$/ $\mathrm{N}-\mathrm{H}(3) \cdots \mathrm{O}=$ ] (Table 1). Thus, in the IR spectrum of the 
TABLE 3: Peak Frequencies $\left(\mathrm{cm}^{-1}\right)$, Qualitative Intensities, ${ }^{a}$ and Assignment of Bands in the Infrared Spectra of Pristine and Isotopically Diluted DL-Ser $\cdot \mathrm{HCl}$ Polycrystals at $10 \mathrm{~K}$, in the Range $4000-400 \mathrm{~cm}^{-1 b}$

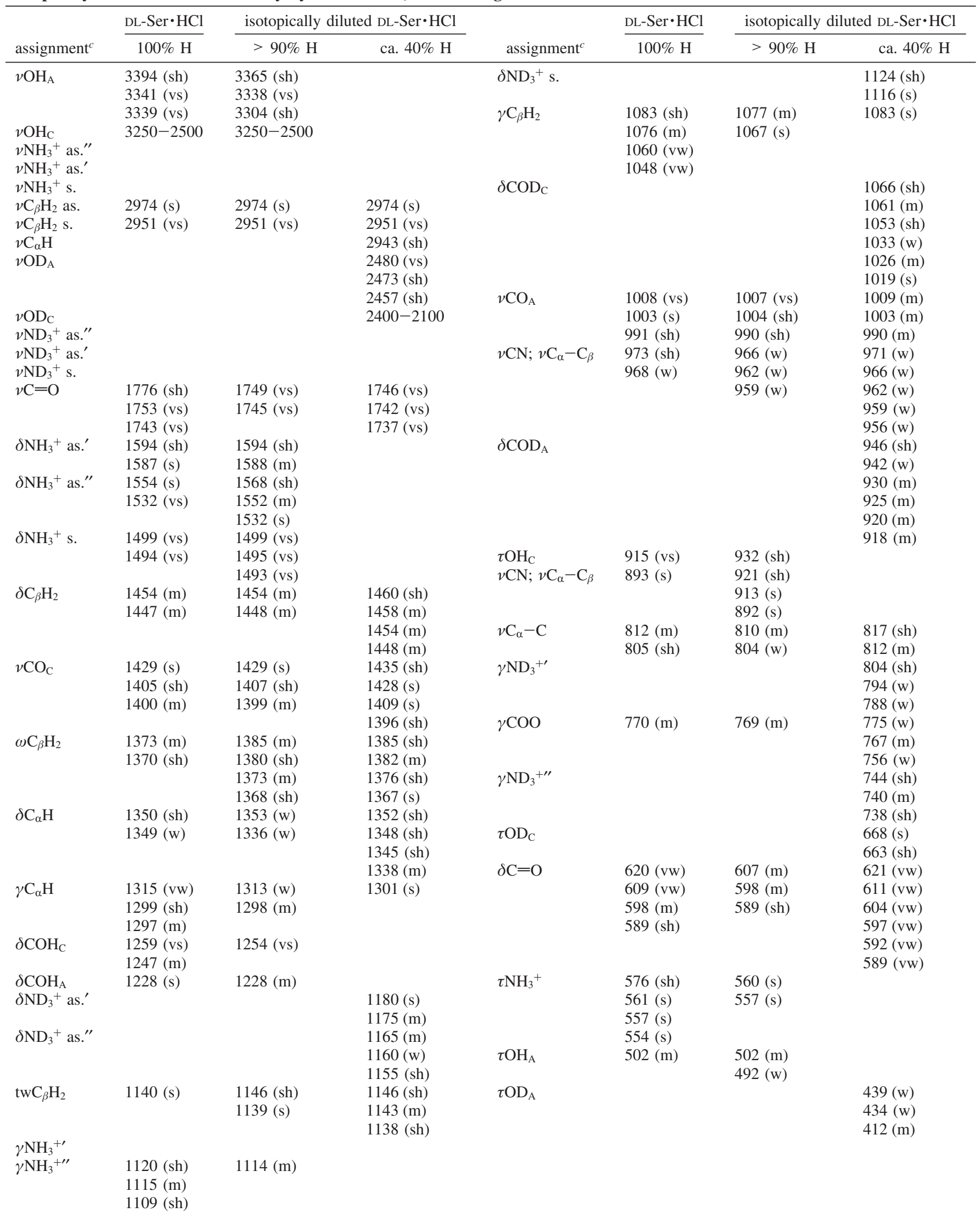

${ }^{a}$ (vs) - very strong; (s) - strong; (m) - medium; (w) - weak; (vw) - very weak; (sh) - shoulder. ${ }^{b}$ In reference to the OH groups, the subscript A stands for alcohol, while the subscript $\mathrm{C}$ stands for carboxylic group. ${ }^{c} \nu$ - bond stretching; $\delta$ - bending; $\omega$ - wagging; $\gamma$ - rocking (out-of-plane); tw - twisting; $\tau$ - torsion; as. - asymmetric; s. - symmetric. 
TABLE 4: Peak Frequencies $\left(\mathrm{cm}^{-1}\right)$ and Assignment of the Bands of Uncoupled $\mathrm{NH} / \mathrm{OH}_{\mathrm{A} / \mathrm{C}}$ and ND/OD $/ \mathrm{C}$ Modes in Isotopically Diluted DL-Ser $\cdot \mathrm{HCl}$ Polycrystals at $10 \mathrm{~K}$, in the Range $4000-400 \mathrm{~cm}^{-1} a$

\begin{tabular}{|c|c|c|}
\hline \multirow[b]{2}{*}{ assignment $^{b}$} & \multicolumn{2}{|c|}{ isotopically diluted $\mathrm{DL}-\mathrm{Ser} \cdot \mathrm{HCl}$} \\
\hline & $\begin{array}{c}>90 \% \mathrm{H} \\
\left(-\mathrm{NDH}_{2}^{+} ; \mathrm{OD}_{\mathrm{A} / \mathrm{C}}\right)\end{array}$ & $\begin{array}{c}\text { ca. } 40 \% \mathrm{H} \\
\left(-\mathrm{NHD}_{2}^{+} ; \mathrm{OH}_{\mathrm{A} / \mathrm{C}}\right)\end{array}$ \\
\hline \multirow[t]{3}{*}{$\nu \mathrm{OH}_{\mathrm{A}}$} & & 3371 \\
\hline & & 3332 \\
\hline & & 3288 \\
\hline$\nu \mathrm{OH}_{\mathrm{C}}$ & & overlapped \\
\hline$v \mathrm{~N}-\mathrm{H}(1)$ & & 3100 \\
\hline$v \mathrm{~N}-\mathrm{H}(2)$ & & 3036 \\
\hline$v \mathrm{~N}-\mathrm{H}(3)$ & & 3010 \\
\hline \multirow{3}{*}{$v \mathrm{OD}_{\mathrm{A}}$} & 2472 & \\
\hline & 2456 & \\
\hline & 2442 & \\
\hline$v \mathrm{OD}_{\mathrm{C}}$ & overlapped & \\
\hline$v \mathrm{~N}-\mathrm{D}(1)$ & 2274 & \\
\hline$v \mathrm{~N}-\mathrm{D}(2)$ & 2240 & \\
\hline$v \mathrm{~N}-\mathrm{D}(3)$ & 2233 & \\
\hline \multirow[t]{2}{*}{$\delta \mathrm{N}-\mathrm{H}(3)$} & & 1597 \\
\hline & & 1588 \\
\hline \multirow[t]{2}{*}{$\delta \mathrm{N}-\mathrm{H}(2)$} & & 1575 \\
\hline & & 1571 \\
\hline \multirow[t]{2}{*}{$\delta \mathrm{N}-\mathrm{H}(1)$} & & 1560 \\
\hline & & 1555 \\
\hline \multirow[t]{5}{*}{$\delta \mathrm{COH}_{\mathrm{C}}$} & & 1277 \\
\hline & & 1274 \\
\hline & & 1261 \\
\hline & & 1256 \\
\hline & & 1253 \\
\hline \multirow[t]{2}{*}{$\delta \mathrm{COH}_{\mathrm{A}}$} & & 1239 \\
\hline & & 1233 \\
\hline$\delta \mathrm{N}-\mathrm{D}(3)$ & 1169 & \\
\hline$\delta \mathrm{N}-\mathrm{D}(2)$ & 1098 & \\
\hline$\delta \mathrm{N}-\mathrm{D}(1)$ & 1089 & \\
\hline$\gamma \mathrm{N}-\mathrm{H}(3)$ & & 1108 \\
\hline$\gamma \mathrm{N}-\mathrm{H}(2)$ & & 1101 \\
\hline$\gamma \mathrm{N}-\mathrm{H}(1)$ & & 1095 \\
\hline \multirow[t]{2}{*}{$\delta \mathrm{COD}_{\mathrm{C}}$} & 1045 & \\
\hline & 1025 & \\
\hline$\delta \mathrm{COD}_{\mathrm{A}}$ & overlapped & \\
\hline$\tau \mathrm{OH}_{\mathrm{C}}$ & & $905-825$ \\
\hline$\gamma \mathrm{N}-\mathrm{D}(3)$ & 866 & \\
\hline$\gamma \mathrm{N}-\mathrm{D}(2)$ & 853 & \\
\hline \multirow[t]{3}{*}{$\gamma \mathrm{N}-\mathrm{D}(1)$} & 801 & \\
\hline & 795 & \\
\hline & 792 & \\
\hline \multirow[t]{2}{*}{$\tau \mathrm{OD}_{\mathrm{C}}$} & 668 & \\
\hline & 664 & \\
\hline \multirow[t]{7}{*}{$\tau \mathrm{OH}_{\mathrm{A}}$} & & 540 \\
\hline & & 536 \\
\hline & & 531 \\
\hline & & 527 \\
\hline & & 500 \\
\hline & & 492 \\
\hline & & 484 \\
\hline
\end{tabular}

${ }^{a}$ In reference to the $\mathrm{OH}$ groups, the subscript A stands for alcohol, while the subscript $\mathrm{C}$ stands for carboxylic group. See Table 1 for numbering of hydrogen atoms involved in $\mathrm{H}$-bonding. ${ }^{b} \mathrm{~V}$ - bond stretching; $\delta$ - bending; $\gamma$ - rocking (out-of-plane); $\tau$ - torsion.

crystal, the bands due to the $v \mathrm{NH}_{3}{ }^{+}$vibrations are expected to appear at much lower wavenumbers than those calculated for the monomer, namely, in the same range as the $\mathrm{CH}$ stretching vibrations. Moreover, as mentioned above, the $\mathrm{OH}_{\mathrm{C}}$ stretching mode also contributes to absorption in this spectral range. As a result, it is difficult to do a detailed assignment in this region of spectrum for the nondeuterated compound. However, as

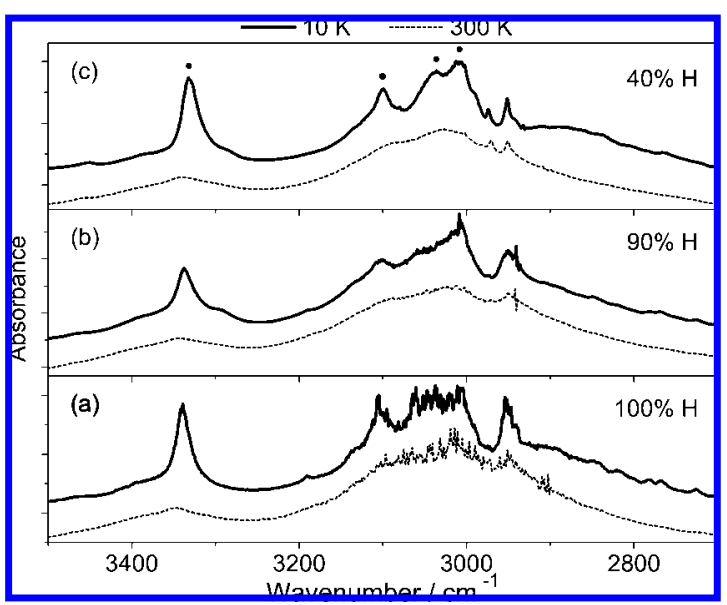

Figure 2. $3500-2700 \mathrm{~cm}^{-1}$ spectral range $(\mathrm{X}-\mathrm{H}$ stretching vibrations; $\mathrm{X}=\mathrm{C}, \mathrm{N}, \mathrm{O}$ ) of the IR spectra of $\mathrm{DL}-\mathrm{Ser} \cdot \mathrm{HCl}$ containing: (a) natural isotopic composition $(\sim 100 \% \mathrm{H}),(\mathrm{b})>90 \% \mathrm{H}$, and (c) ca. $40 \% \mathrm{H}$. In all frames, the dashed lines correspond to samples at room temperature $(300 \mathrm{~K})$, and the solid lines correspond to maximum cooling $(10 \mathrm{~K})$. The bands marked with a circle are due to the uncoupled modes and are discussed in the text.

shown below, the isotopic doping technique allows one to distinguish between these proton-related modes in the IR spectra of D-doped DL-Ser $\cdot \mathrm{HCl}$ crystal.

Crystal Doped with Minority H Molecules (Figure 2c). In the spectrum recorded at room temperature, the quite intense and broad band at ca. $3341 \mathrm{~cm}^{-1}$ is assigned to the $\mathrm{OH}$ stretching mode of the alcoholic group. This band becomes narrower and more intense upon cooling. At $10 \mathrm{~K}$, this vibration gives rise to a band with a main maximum at $3332 \mathrm{~cm}^{-1}$. The spectral position of this band is in agreement with the frequency of the $\mathrm{OH}$ stretching vibration in the nondeuterated sample (Figure 2a).

When the percentage of deuteration of $\mathrm{DL}-\mathrm{Ser} \cdot \mathrm{HCl}$ is above $60 \% \mathrm{D}$, the vibrations of the $\mathrm{NH}$ bond become uncoupled from the remaining two ND bonds in the partially deuterated ammonium group $\left(-\mathrm{NHD}_{2}{ }^{+}\right)$. In the spectral region characteristic of the $v \mathrm{NH}$ vibrations, several bands were observed, whose maxima, at $10 \mathrm{~K}$, are located at 3100,3036 , and $3010 \mathrm{~cm}^{-1}$ (Table 4). They correspond to the vibrations related with the hydrogen bonds of increasing strength present in the crystal, $\mathrm{N}-\mathrm{H}(1) \cdots \mathrm{Cl}^{-}, \mathrm{N}-\mathrm{H}(2) \cdot \mathrm{Cl}^{-}$, and $\mathrm{N}-\mathrm{H}(3) \cdots \mathrm{Cl}^{-}$/ $\mathrm{N}-\mathrm{H}(3) \cdots \mathrm{O}=$, respectively (with associated $\mathrm{N}-\mathrm{H}$ bond lengths of $0.8544,0.8768$ and $0.9332 \AA$, respectively; see Table $1)$. The ND stretching vibrations of $-\mathrm{NHD}_{2}{ }^{+}$and $-\mathrm{ND}_{3}{ }^{+}$ groups are assigned to bands in the $2400-2100 \mathrm{~cm}^{-1}$ range (Figure 3c).

In the crystal of DL-Ser $\cdot \mathrm{HCl}$, the $\mathrm{OH}_{\mathrm{C}}$ group is involved in an $\mathrm{O}-\mathrm{H}_{\mathrm{C}} \cdots \mathrm{O}_{\mathrm{A}} \mathrm{H}$-bond, which is much stronger than the H-bond of the $\mathrm{OH}_{\mathrm{A}}$ group, $\mathrm{O}-\mathrm{H}_{\mathrm{A}} \cdot \mathrm{Cl}^{-}$, (see Table 1 for geometric parameters). The more elongated $\mathrm{O}-\mathrm{H}_{\mathrm{C}}$ bond should give rise to the absorption band (originated in the $\mathrm{O}-\mathrm{H}_{\mathrm{C}}$ stretching vibration) that appears at a much lower wavenumber and should be much more broadened. Since there are no obvious candidates for this absorption in the experimental spectra, we suggest that the spectral position of the broad $\mathrm{OH}_{\mathrm{C}}$ stretching band has a frequency similar to that of the ammonium stretching vibrations. The broad spectral envelope in the $3250-2700 \mathrm{~cm}^{-1}$ region cannot be attributed exclusively to the $\mathrm{NH}$ stretching vibrations and, with all probability, also includes the contribution due to the band of the $\mathrm{OH}_{\mathrm{C}}$ stretching mode. ${ }^{29}$

The narrow bands observed at 2974 and $2951 \mathrm{~cm}^{-1}$ with a shoulder at $2943 \mathrm{~cm}^{-1}$ at $10 \mathrm{~K}$ are undoubtedly assigned to 


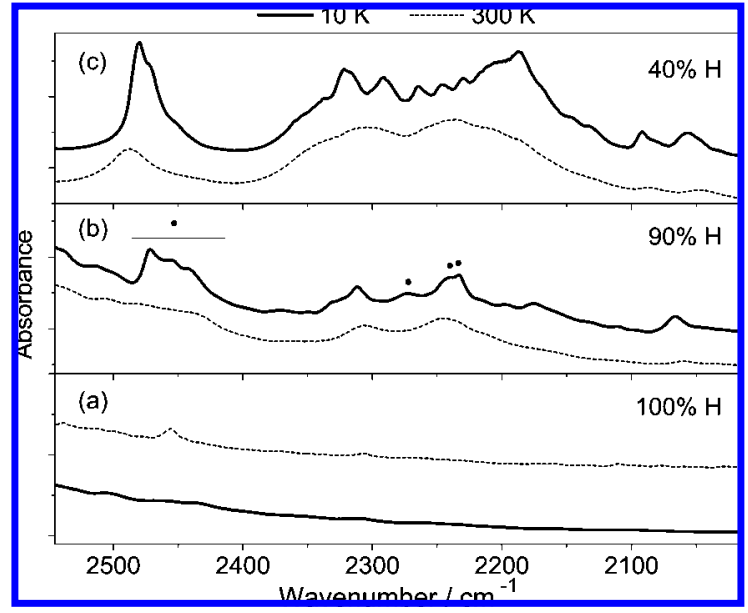

Figure 3. $2550-2000 \mathrm{~cm}^{-1}$ spectral range $(X-D$ stretching vibrations; $\mathrm{X}=\mathrm{N}, \mathrm{O}$ ) of the IR spectra of DL-Ser $\cdot \mathrm{HCl}$ containing (a) natural isotopic composition $(\sim 100 \% \mathrm{H}),(\mathrm{b})>90 \% \mathrm{H}$, and (c) ca. $40 \% \mathrm{H}$. In all frames, the dashed lines correspond to samples at room temperature $(300 \mathrm{~K})$, and the solid lines correspond to maximum cooling $(10 \mathrm{~K})$. The bands marked with a circle are due to the uncoupled modes and are discussed in the text.

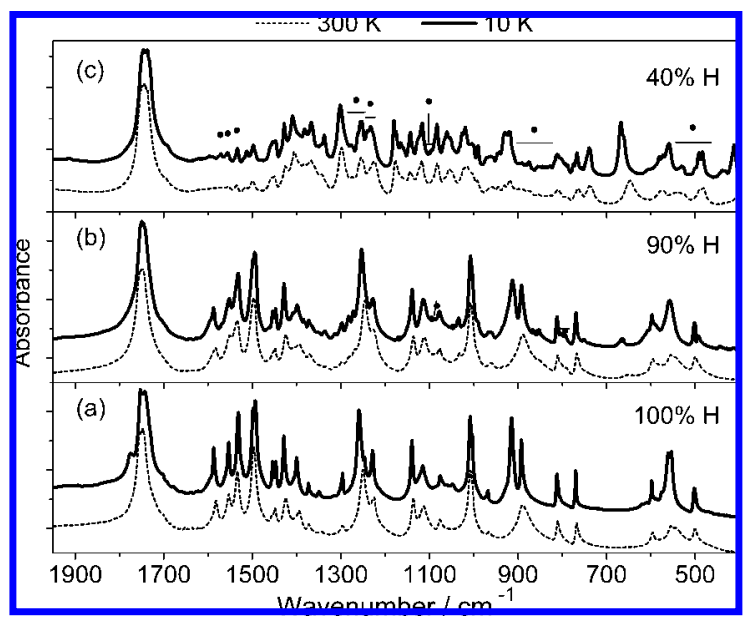

Figure 4. $1900-400 \mathrm{~cm}^{-1}$ spectral range (fingerprint region) of the IR spectra of DL-Ser $\cdot \mathrm{HCl}$ containing (a) natural isotopic composition $(\sim 100 \% \mathrm{H}),(\mathrm{b})>90 \% \mathrm{H}$, and (c) ca. $40 \% \mathrm{H}$. In all frames, the dashed lines correspond to samples at room temperature $(300 \mathrm{~K})$, and the solid lines correspond to maximum cooling $(10 \mathrm{~K})$. The bands marked with a circle are due to the uncoupled modes and are discussed in the text.

$\nu \mathrm{C}_{\beta} \mathrm{H}_{2}$ as. and $\nu \mathrm{C}_{\beta} \mathrm{H}_{2} \quad$ s. $/ \nu \mathrm{C}_{\alpha} \mathrm{H}$, respectively (Table 3). As expected, these vibrations do not differ much from the corresponding vibrations in crystals of DL-Ser $v \mathrm{C}_{\beta} \mathrm{H}_{2}$ as. -2971 $\mathrm{cm}^{-1} ; \nu \mathrm{C}_{\beta} \mathrm{H}_{2}$ s. $\left./ v \mathrm{C}_{\alpha} \mathrm{H}-2943 \mathrm{~cm}^{-1}\right)^{4}$ and L-Ser $\left(\nu \mathrm{C}_{\beta} \mathrm{H}_{2}\right.$ as. $3004 \mathrm{~cm}^{-1} ; \nu \mathrm{C}_{\beta} \mathrm{H}_{2}$ s. $\left.-2943 \mathrm{~cm}^{-1} ; \nu \mathrm{C}_{\alpha} \mathrm{H}-2905 \mathrm{~cm}^{-1}\right) .^{5}$

Crystal Doped with Minority D Molecules (Figure 3b). In the low-temperature IR spectrum of the DL-Ser $\cdot \mathrm{HCl}$ crystal with a low concentration of deuterium, a band with three main maxima at 2472, 2456, and $2442 \mathrm{~cm}^{-1}$ is well resolved and assigned to the $v \mathrm{OD}$ vibrations of the alcohol group (Table 4).

The broad band with maximum at room temperature at 2246 $\mathrm{cm}^{-1}$ shows a substantial change in its profile and a red shift upon cooling. At $10 \mathrm{~K}$, the band is split into several components, with maxima at 2274, 2240, and $2233 \mathrm{~cm}^{-1}$, which correspond to the three uncoupled $v \mathrm{ND}$ vibrations of the $-\mathrm{NDH}_{2}{ }^{+}$deuterons involved in the three different $\mathrm{H}$-bonds involving the ammonium group existing in the crystal (Tables 1 and 4).
The isotopic ratios of the three isotopically decoupled pairs of $\mathrm{NH} / \mathrm{ND}$ stretching bands (at $10 \mathrm{~K}$ ), $\mathrm{N}-\mathrm{H}(1) \cdots \mathrm{Cl}^{-}$, $\mathrm{N}-\mathrm{H}(2) \cdots \mathrm{Cl}^{-}$and $\mathrm{N}-\mathrm{H}(3) \cdots \mathrm{Cl}^{-} / \mathrm{N}-\mathrm{H}(3) \cdots \mathrm{O}=$, are 1.363 , 1.355 , and 1.348 , respectively. These isotopic ratios are consistent with the values found previously for other amino acids $^{4}$ and support the assignment of these bands to the stretching mode originated in each one of the three individual $\mathrm{N}-\mathrm{H}$ or $\mathrm{N}-\mathrm{D}$ bonds in $-\mathrm{NH}_{3}{ }^{+}$or $-\mathrm{ND}_{3}{ }^{+}$groups.

Spectral Range below $2000 \mathrm{~cm}^{-1}$ (Fingerprint Region). Unlike the carboxylate stretching bands observed in the IR spectra of zwitterionic amino acids $\left[v \mathrm{COO}^{-}\right.$asymmetric (ca. $1600 \mathrm{~cm}^{-1}$ ) and $\nu \mathrm{COO}^{-}$symmetric (ca. $1400 \mathrm{~cm}^{-1}$ )], ${ }^{4,5,26}$ a single band at a frequency typical of the carbonyl bond stretching of the carboxylic group $(\mathrm{O}=\mathrm{C}-\mathrm{O}-\mathrm{H})$ in protonated amino acids ${ }^{26}$ is observed in the IR spectrum of DL-Ser $\cdot \mathrm{HCl}$ (about $1747 \mathrm{~cm}^{-1}$ ). In the IR spectrum of matrix-isolated serine, the $v \mathrm{C}=\mathrm{O}$ vibrations appear at higher wavenumbers; six main bands due to monomeric serine were observed between 1850 and $1740 \mathrm{~cm}^{-1} .^{2}$ The lower frequency of the $\mathrm{C}=\mathrm{O}$ stretching vibrations observed in the crystals indicates that the carbonyl group is, in this case, involved in a stronger hydrogen bond interaction than in the matrix isolated monomers.

The bands due to the $\delta \mathrm{COH}$ of alcohol and acid groups, and those ascribable to the deformation modes of the $-\mathrm{NH}_{3}{ }^{+}$group (three bending and two rocking modes) can be easily identified by comparing the spectrum of deuterium-free $\mathrm{DL}-\mathrm{Ser} \cdot \mathrm{HCl}$ (Figure $4 \mathrm{a}$ ) with that of DL-Ser $\cdot \mathrm{HCl}$ with high deuterium content (Figure 4c), where the bands due to these vibrations have vanishing intensity. The $\delta \mathrm{NH}_{3}{ }^{+}$as.', $\delta \mathrm{NH}_{3}{ }^{+}$as." and $\delta \mathrm{NH}_{3}{ }^{+}$s. modes are then assigned to the pairs of bands at $1594 / 1587$, $1554 / 1532$, and $1499 / 1494 \mathrm{~cm}^{-1}$, respectively, which exhibit strong temperature dependence and noticeably reduce their intensity in the spectra of $-\mathrm{NHD}_{2}{ }^{+}$doped crystals. In turn, the $\delta \mathrm{COH}_{\mathrm{C}}$ and $\delta \mathrm{COH}_{\mathrm{A}}$ modes are assigned to the bands at $1259 / 1247$ and $1228 \mathrm{~cm}^{-1}$, respectively (Table 3 ). As it could be anticipated, the $\delta \mathrm{COH}$ bands show a pronounced dependence on temperature (Figure 4a). The $\delta \mathrm{COH}_{\mathrm{A}}$ vibration was assigned to the bands at 1224,1218 , and $1209 \mathrm{~cm}^{-1}$ in the IR spectrum of the L-Ser crystal and at $1249 \mathrm{~cm}^{-1}$ in the spectrum of DL-Ser crystal. ${ }^{4,5}$ It is worth mentioning that $\delta \mathrm{COH}_{\mathrm{A}}$ appears at considerably lower wavenumbers in the vibrational spectra of $\mathrm{DL}-\mathrm{Ser} \cdot \mathrm{HCl}$ and L-Ser when compared with DL-Ser crystal, in agreement with the much weaker $\mathrm{H}$-bond formed by the $-\mathrm{CH}_{2} \mathrm{OH}$ side chain in DL-Ser $\cdot \mathrm{HCl}$ and $\mathrm{L}-\mathrm{Ser}$ crystals compared to that of DL-Ser. ${ }^{4,5}$

The rocking modes of the ammonium group $\left(\mathrm{NHH}_{3}{ }^{+\prime}\right.$ and $\left.\gamma \mathrm{NH}_{3}{ }^{+\prime \prime}\right)$ were assigned to the bands at 1140 and $1115 \mathrm{~cm}^{-1}$. The $\mathrm{twC}_{\beta} \mathrm{H}_{2}$ mode also contributes to the band at $1140 \mathrm{~cm}^{-1}$ (Table 3). These assignments were based on the comparison with the frequencies of the same modes in the crystals of DLand L-Ser. 4,5

On the basis of the DFT(B3LYP)/6-311++G(d,p) frequency calculations, $\nu \mathrm{CO}_{\mathrm{C}}=1377 \mathrm{~cm}^{-1}$ and $\nu \mathrm{CO}_{\mathrm{A}}=1015 \mathrm{~cm}^{-1}$ (Table S3), and also on the relative bond lengths obtained by $\mathrm{X}$-ray diffraction, $d \mathrm{CO}_{\mathrm{C}}=1.31 \AA$ and $d \mathrm{CO}_{\mathrm{A}}=1.42 \AA$, the $v \mathrm{CO}_{\mathrm{C}}$ and $\nu \mathrm{CO}_{\mathrm{A}}$ vibrations were assigned to the groups of bands at $1429 / 1405 / 1400 \mathrm{~cm}^{-1}$ and $1008 / 1003 / 991 \mathrm{~cm}^{-1}$, respectively (Table 3).

The assignments of deformational vibrations of methylene $\left(\delta \mathrm{C}_{\beta} \mathrm{H}_{2}, \omega \mathrm{C}_{\beta} \mathrm{H}_{2}, \mathrm{twC}_{\beta} \mathrm{H}_{2}\right.$, and $\left.\gamma \mathrm{C}_{\beta} \mathrm{H}_{2}\right)$ and methyne $\left(\delta \mathrm{C}_{\alpha} \mathrm{H}\right.$ and $\left.\gamma \mathrm{C}_{\alpha} \mathrm{H}\right)$ groups are collected in Table 3 . These assignments were carried out on the basis of comparison of these modes in DL-Ser $\cdot \mathrm{HCl}$ crystal with the corresponding modes in the DL- and L-Ser crystals, ${ }^{4,5}$ which were found to give rise to bands 
TABLE 5: H-Bond Enthalpies Estimated for the Different H-Bonds Present in the Crystals of DL-Ser-HCl, DL-Ser, and L-Ser

\begin{tabular}{ccccc}
\hline $\mathrm{DL}-\mathrm{Ser} \cdot \mathrm{HCl}$ & $-\Delta H / \mathrm{kJ} \mathrm{mol}^{-1}$ & $\mathrm{DL}-\mathrm{Ser}$ & $-\Delta H / \mathrm{kJ} \mathrm{mol}^{-1}$ & \multicolumn{2}{c}{$-\mathrm{Ser}^{-\Delta H / \mathrm{kJ} \mathrm{mol}^{-}}$} \\
\hline $\mathrm{O}-\mathrm{H}_{\mathrm{A}} \cdots \mathrm{Cl}^{-}$ & 17 & $\mathrm{O}-\mathrm{H}_{\mathrm{A}} \cdots \mathrm{O}_{\mathrm{C}}$ & 33 & $\mathrm{O}-\mathrm{H}_{\mathrm{A}} \cdots \mathrm{O}_{\mathrm{A}}$ \\
$\mathrm{N}-\mathrm{H}(1) \cdots \mathrm{Cl}^{-}$ & 20 & $\mathrm{~N}-\mathrm{H}(1) \cdots \mathrm{O}_{\mathrm{C}}$ & 21 & $\mathrm{~N}-\mathrm{H}(1) \cdots \mathrm{O}_{\mathrm{C}}$ \\
$\mathrm{N}-\mathrm{H}(2) \cdots \mathrm{Cl}^{-}$ & 23 & $\mathrm{~N}-\mathrm{H}(2) \cdots \mathrm{O}_{\mathrm{C}}$ & 23 & $\mathrm{~N}-\mathrm{H}(2) \cdots \mathrm{O}_{\mathrm{C}}$ \\
$\mathrm{N}-\mathrm{H}(3) \cdots \mathrm{Cl}^{-}$ & 24 & $\mathrm{~N}-\mathrm{H}(3) \cdots \mathrm{O}_{\mathrm{A}}$ & 24 & $\mathrm{~N}-\mathrm{H}(3) \cdots \mathrm{O}_{\mathrm{C}}$
\end{tabular}

at nearly the same positions. In particular, the proposed assignments are $\delta \mathrm{C}_{\beta} \mathrm{H}_{2}$ to the doublet at $1454 / 1447 \mathrm{~cm}^{-1}$ (1451 $\mathrm{cm}^{-1}$ in DL-Ser ${ }^{4}$ and $1470 / 1459 \mathrm{~cm}^{-1}$ in $\left.\mathrm{L}-\mathrm{Ser}^{5}\right) ; \omega \mathrm{C}_{\beta} \mathrm{H}_{2}$ to the band at $1373 \mathrm{~cm}^{-1}$ with a shoulder at $1370 \mathrm{~cm}^{-1}(1375 / 1372$ $\mathrm{cm}^{-1}$ in DL-Ser ${ }^{4}$ and four bands in the $1390-1350 \mathrm{~cm}^{-1}$ region in $\left.\mathrm{L}-\mathrm{Ser}^{5}\right) ; \mathrm{twC}_{\beta} \mathrm{H}_{2}$ to the band at $1140 \mathrm{~cm}^{-1}\left(1189 \mathrm{~cm}^{-1}\right.$ in DL-Ser ${ }^{4}$ and $1140 \mathrm{~cm}^{-1}$ in L-Ser $\left.{ }^{5}\right) ; \gamma \mathrm{C}_{\beta} \mathrm{H}_{2}$ to the group of bands in the $1085-1045 \mathrm{~cm}^{-1}$ region $\left(1065-1025 \mathrm{~cm}^{-1}\right.$ in DL-Ser ${ }^{4}$ and the doublet at $1022 / 1015 \mathrm{~cm}^{-1}$ in $\left.\mathrm{L}-\mathrm{Ser}^{5}\right) ; \delta \mathrm{C}_{\alpha} \mathrm{H}$ to the weak band at $1349 \mathrm{~cm}^{-1}$ with a shoulder at $1350 \mathrm{~cm}^{-1}(1363 / 1355$ $\mathrm{cm}^{-1}$ in DL-Ser ${ }^{4}$ and $1339 / 1330 \mathrm{~cm}^{-1}$ in $\left.\mathrm{L}-\mathrm{Ser}^{5}\right)$; and $\gamma \mathrm{C}_{\alpha} \mathrm{H}$ to a set of bands at 1315/1299/1297 $\mathrm{cm}^{-1}\left(1321 / 1315 / 1303 \mathrm{~cm}^{-1}\right.$ in DL-Ser ${ }^{4}$ and a group of bands in the $1315-1300 \mathrm{~cm}^{-1}$ region in $\mathrm{L}-S e r^{5}$ ). It is worth noting that the bands ascribed to the bending vibrations of both the $-\mathrm{CH}_{2}$ and $-\mathrm{CH}$ groups show a substantial dependence on temperature, clearly indicating that these modes are considerably coupled with vibrations originating in the $-\mathrm{NH}_{3}{ }^{+}$or/and $-\mathrm{OH}$ groups.

The $\tau \mathrm{OH}_{\mathrm{C}}, \tau \mathrm{OH}_{\mathrm{A}}$, and $\tau \mathrm{NH}_{3}{ }^{+}$modes appear below 1000 $\mathrm{cm}^{-1}$. The bands corresponding to $\tau \mathrm{OH}_{\mathrm{C}}$ and $\tau \mathrm{NH}_{3}{ }^{+}$vibrations were observed at $915 / 893 \mathrm{~cm}^{-1}$ and $580-550 \mathrm{~cm}^{-1}$, respectively. Among all bands in the spectra of the different crystals, these features exhibit the most pronounced temperature dependence, strongly increasing in peak intensity and shifting to higher frequencies upon cooling (Figure 4a). This behavior could have been anticipated considering the nature of the modes and the direct involvement of the acid and ammonium protons in the $\mathrm{H}$-bond network of the crystals. Contrarily to the bands ascribed to the $\tau \mathrm{OH}_{\mathrm{C}}$ and $\tau \mathrm{NH}_{3}{ }^{+}$modes, the band assigned to the $\tau \mathrm{OH}_{\mathrm{A}}$ vibration $\left(502 \mathrm{~cm}^{-1}\right)$ does not exhibit pronounced temperature dependence. In the IR spectrum of DL-Ser crystal, ${ }^{4}$ the $\tau \mathrm{OH}_{\mathrm{A}}$ mode appears at $744 \mathrm{~cm}^{-1}$ and in the IR spectrum of L-Ser crystal in the $500-420 \mathrm{~cm}^{-1}$ range..$^{5}$ As it was mentioned above, the $\mathrm{H}$-bond formed by the $\mathrm{O}-\mathrm{H}_{\mathrm{A}}$ group in the crystal of $\mathrm{DL}-\mathrm{Ser} \cdot \mathrm{HCl}$ is weaker than in DL-Ser and stronger than in L-Ser crystals. That is then in agreement with the observation of the band due to $\tau \mathrm{OH}_{\mathrm{A}}$ mode in the DL-Ser $\cdot \mathrm{HCl}$ crystal between those found in the IR spectra of DL- and L-Ser crystals. ${ }^{4,5}$

Finally, the $\gamma \mathrm{COO}$ and $\delta \mathrm{C}=\mathrm{O}$ modes do also absorb in this spectral range. These modes were assigned to the band at $770 \mathrm{~cm}^{-1}$ and the multiplet at $620 / 609 / 598 / 589 \mathrm{~cm}^{-1}$, respectively (Figure 4a and Table 3), based on the DFT(B3LYP)/6$311++\mathrm{G}(\mathrm{d}, \mathrm{p})$ calculations, which predict the $\gamma \mathrm{COO}$ and $\delta \mathrm{C}=\mathrm{O}$ modes to appear at about 800 and $600 \mathrm{~cm}^{-1}$, respectively (Table S3).

Crystal Doped with Minority H Molecules (Figure 4c). In the spectrum of the crystal doped with minority $\mathrm{H}$ molecules, new low intensity bands are observed, which belong to the uncoupled $\mathrm{NH}$ and $\mathrm{ND}_{2}$ deformational modes of the $-\mathrm{NHD}_{2}{ }^{+}$ group, as well as to the $\mathrm{OH}_{\mathrm{A}}$ and $\mathrm{OH}_{\mathrm{C}}$ modes. These weak bands can be clearly seen only in the spectra collected at lower temperatures, and they exhibit a blue shift on cooling. The bands observed in the spectral range $1610-1480 \mathrm{~cm}^{-1}$, whose maxima, at $10 \mathrm{~K}$, are at 1597,1571 , and $1555 \mathrm{~cm}^{-1}$, are assigned to the three $\delta \mathrm{NH}$ uncoupled vibrations, $\delta \mathrm{N}-\mathrm{H}(3), \delta \mathrm{N}-\mathrm{H}(2)$, and $\delta \mathrm{N}-\mathrm{H}(1)$, respectively (Table 4$)$. On the other hand, the bands observed in the spectrum recorded at room temperature at 1274 and $1254 \mathrm{~cm}^{-1}$ are assigned to the $\delta \mathrm{COH}_{\mathrm{C}}$ vibration, and that at $1225 \mathrm{~cm}^{-1}$ is assigned to the $\delta \mathrm{COH}_{\mathrm{A}}$ vibration. These three bands show a blue shift and become much more structured upon cooling (Table 4).

The bending vibrations related with the $-\mathrm{ND}_{3}{ }^{+}$group of the (bulk) deuterated molecules appear at much lower wavenumbers: $1180 / 1175 \mathrm{~cm}^{-1}, 1165 / 1160 \mathrm{~cm}^{-1}$, and $1116 \mathrm{~cm}^{-1}$, assigned respectively to the $\delta \mathrm{ND}_{3}{ }^{+}$as.', $\delta \mathrm{ND}_{3}{ }^{+}$as." and $\delta \mathrm{ND}_{3}{ }^{+}$s. modes (Table 3 ). In turn, the $\delta \mathrm{COD}_{\mathrm{C}}$ vibration is assigned to the medium-intensity bands whose maxima at room temperature are observed at 1055 and $1016 \mathrm{~cm}^{-1}$, and the $\delta \mathrm{COD}_{\mathrm{A}}$ mode gives rise to bands in the $950-900 \mathrm{~cm}^{-1}$ region (Table 3). All these bands show a blue shift upon cooling.

To estimate the position of the uncoupled $\gamma \mathrm{NH}$ bands, we used the empirical correlation ${ }^{30}$ between the red shift of the uncoupled $v \mathrm{NH}$ bands in the crystal (relative to the frequency of a similar mode in a non-hydrogen-bonded molecule) and the blue shift of the band due to the corresponding out-of-plane mode. Following conventional Herzberg's notation, the protonrelated stretching modes will here be designated as $v_{1}$, while $v_{4}$ will stand for the out-of-plane rocking modes of the same group. The red shift of $v_{1}$ and the blue shift of $v_{4}$ modes associated with a given proton correlate as

$$
\Delta v_{4}^{2}=2.5\left(\Delta v_{1}\right)^{1 / 2}-18
$$

where $\Delta v_{4}^{2} \equiv 10^{-4}\left[\left(v_{4}\right)^{2}-\left(v_{4}^{0}\right)^{2}\right]$ and $\Delta v_{1}=v_{1}^{0}-v_{1}$ (both $v_{1}$ and $v_{4}$ are expressed in $\left.\mathrm{cm}^{-1}\right){ }^{30}$ The $v_{1}^{0}$ and $v_{4}{ }^{0}$ reference values will be taken as 3450 and $1000 \mathrm{~cm}^{-1}$, respectively, which correspond to rounded average values for free $\mathrm{NH}$ amine stretching and rocking vibrations in amines, amino acids, and other compounds bearing amino groups. ${ }^{1,8,31}$ Then, according to the correlation above, the three out-of-plane uncoupled vibrations originating in individual $\mathrm{NH}$ protons are predicted at 1148,1141 , and $1124 \mathrm{~cm}^{-1}$. These frequencies can be associated with the three progressively weaker $\mathrm{N}-\mathrm{H}^{\circ} \cdot \mathrm{Cl}^{-}$ bonds formed in the crystalline phase. In the experimental spectrum of $\mathrm{DL}-\mathrm{Ser} \cdot \mathrm{HCl}$ with ca. $60 \% \mathrm{D}$, two bands with the required characteristics (low intensity, substantial dependence on temperature, absence in the spectra of the remaining crystals here studied) are observed at 1101 and $1095 \mathrm{~cm}^{-1}$, fairly close to the predicted frequencies, and were then assigned to the uncoupled $\gamma \mathrm{NH}$ modes associated with the two weakest $\mathrm{N}-\mathrm{H} \cdots \mathrm{Cl}^{-}$bonds (Table 4). The band originated in the rocking vibration of the remaining proton is much probably buried underneath the intense band due to the $\delta \mathrm{ND}_{3}{ }^{+} \mathrm{s}$. bulk mode at $1116 \mathrm{~cm}^{-1}$ (see Table 3). Indeed, there is a shoulder at $1108 \mathrm{~cm}^{-1}$, which can be tentatively assigned to the $\gamma \mathrm{NH}$ mode associated with the strongest hydrogen bond $\left[\mathrm{N}-\mathrm{H}(3) \cdots \mathrm{Cl}^{-}\right.$/ $\mathrm{N}-\mathrm{H}(3) \cdots \mathrm{O}=]$ (Table 4). The deuterated counterparts of these bands in the spectrum of DL-Ser $\cdot \mathrm{HCl}$ with $\leq 10 \% \mathrm{D}$ (uncoupled $\gamma$ ND modes) are observed at 866,853 , and $801 / 795 / 792 \mathrm{~cm}^{-1}$ (Figure 4b), exhibiting frequency isotopic ratios of 1.279, 1.291, and 1.376 , respectively.

It is interesting to report on the large number of new weak bands that appear in the $905-825 \mathrm{~cm}^{-1}$ range, ascribable to the torsion of the $\mathrm{OH}_{\mathrm{C}}$ group (Table 4) and to the $v \mathrm{CN}$ and 
$v \mathrm{C}_{\alpha}-\mathrm{C}_{\beta}$ skeletal vibrations (Table 3 ). Finally, the bands at 540, 536,531 , and $527 \mathrm{~cm}^{-1}$ are assigned to the torsion of the $\mathrm{OH}_{\mathrm{A}}$ group (Table 4).

Crystal Doped with Minority D Molecules (Figure 4b). As in the spectra of the crystal doped with minority $\mathrm{H}$ molecules (Figure 4c), in the crystal doped with minority D molecules, new and low intensity bands, due to the uncoupled ND and $\mathrm{NH}_{2}$ deformational modes of the $-\mathrm{NDH}_{2}{ }^{+}$group, as well as the $\mathrm{OD}_{\mathrm{A}}$ and $\mathrm{OD}_{\mathrm{C}}$ modes, are observed. These bands show a blue shift upon cooling and can be clearly observed in the spectra collected at lower temperatures.

The bands at 1570 and $1463 \mathrm{~cm}^{-1}$ are assigned to $\delta \mathrm{NH}_{2}$ as. and $\delta \mathrm{NH}_{2}$ s. modes, respectively. Because of their low intensity, both bands become discernible only at low temperatures.

The three bands located at 1169,1098 , and $1089 \mathrm{~cm}^{-1}$ are associated with the uncoupled $\delta \mathrm{ND}$ vibrations of the $\mathrm{D}$-doped molecules in $\mathrm{DL}-\mathrm{Ser} \cdot \mathrm{HCl}$ crystals, which were assigned to $\delta \mathrm{N}-\mathrm{D}(3)\left[\mathrm{N}-\mathrm{D}(3) \cdots \mathrm{Cl}^{-} / \mathrm{N}-\mathrm{D}(3) \cdots \mathrm{O}=\right.$; strongest H-bond], $\delta \mathrm{N}-\mathrm{D}(2)\left[\mathrm{N}-\mathrm{D}(2) \cdots \mathrm{Cl}^{-}\right]$and $\delta \mathrm{N}-\mathrm{D}(1)\left[\mathrm{N}-\mathrm{D}(1) \cdots \mathrm{Cl}^{-}\right.$; weakest H-bond], respectively (Tables 1 and 4).

The very weak bands with maxima at 1045 and $1025 \mathrm{~cm}^{-1}$ were assigned to the $\delta \mathrm{COD}_{\mathrm{C}}$ vibration (Table 4). On the other hand, the $\delta \mathrm{COD}_{\mathrm{A}}$ vibration in DL-Ser $\cdot \mathrm{HCl}$ could be expected to give rise to absorb between 934 and ca. $880 \mathrm{~cm}^{-1}$, which are the frequencies at which the analogous mode absorbs in DL- and L-Ser crystals. ${ }^{4,5}$ However, this spectral region also contains the stronger intensity bands due to the $\tau \mathrm{OH}_{\mathrm{C}}, \nu \mathrm{CN}$, and $v \mathrm{C}_{\alpha}-\mathrm{C}_{\beta}$ vibrations, which precludes a clear observation of the absorption due to the $\delta \mathrm{COD}_{\mathrm{A}}$ mode.

Finally, the band at ca. $665 \mathrm{~cm}^{-1}$, which shows a pronounced blue shift upon cooling ( 15 to $20 \mathrm{~cm}^{-1}$ ), was assigned to the torsion of the $\mathrm{OD}_{\mathrm{C}}$ group in the spectra of two deuterated DL-Ser $\cdot \mathrm{HCl}$ crystals (Tables 3 and 4 ). As expected, this feature does not appear in the spectrum of the sample with natural isotopic abundance.

Characterization of H-bonds: Spectra/Energy Correlations. The observed frequency red shifts of the $v_{1}$ stretching modes and blue shifts of the $v_{4}$ out-of-plane bending modes upon $\mathrm{H}$-bond formation and the corresponding $\mathrm{H}$-bond enthalpies (in $\mathrm{kJ} \mathrm{mol}^{-1}$ ) were shown ${ }^{13,32}$ to obey the empirical correlations:

$$
(\Delta \mathrm{H})^{2}=1.92\left(\Delta v_{1}-40\right)
$$

and

$$
-\Delta \mathrm{H}=0.67 \Delta v_{4}^{2}
$$

These correlations satisfactorily describe a considerable number of H-bonded systems, including crystalline carbohydrates, ${ }^{13,14}$ nucleobases (cytosine, ${ }^{9}$ uracil, and thymine ${ }^{10}$ ), nucleosides (cytidine, ${ }^{10}$ adenosine, and uridine ${ }^{11}$ ) and several amino acids (e.g., glycine, alanine, glutamine, hystidine, tyrosine, and threonine). ${ }^{8}$ They were also successfully validated for crystalline DL- and L-Ser., ${ }^{4,5}$

In order to estimate the H-bond enthalpies using these empirical correlations, a suitable reference frequency value for the non-hydrogen-bonded $\mathrm{NH}$ (or $\mathrm{OH}$ ) $v_{1}$ and $v_{4}$ vibrations in DL-Ser $\cdot \mathrm{HCl}$ shall be defined. The choice of these values for the $\mathrm{N}-\mathrm{H}$ vibrations was presented above (see eq 1 ). Concerning the $\mathrm{O}-\mathrm{H}$ alcohol vibrations, the $v_{1}^{0}$ and $v_{4}^{0}$ reference values were taken as 3640 and $300 \mathrm{~cm}^{-1}$, respectively, which correspond to the calculated scaled frequencies for $v \mathrm{OH}_{\mathrm{A}}$ and $\tau \mathrm{OH}_{\mathrm{A}}$ of isolated serine conformers that do not have the $-\mathrm{OH}$ group involved in any intramolecular $\mathrm{H}$-bond. ${ }^{2}$ These values also closely match the observed frequencies for these two modes in the spectrum of $t$-butanol in $\mathrm{CCl}_{4}$ diluted solutions. ${ }^{32}$

The average $\mathrm{H}$-bond energies resulting from the two empirical correlations presented above for crystalline $\mathrm{DL}-\mathrm{Ser} \cdot \mathrm{HCl}$ are 17 , 20,23 , and $24 \mathrm{~kJ} \mathrm{~mol}^{-1}$, for the $\mathrm{O}-\mathrm{H}_{\mathrm{A}} \cdots \mathrm{Cl}^{-}$and the three $\mathrm{N}-\mathrm{H} \cdot \mathrm{Cl}^{-}$hydrogen bonds, respectively. These values are compared with those obtained using the same empirical correlations for crystalline DL- and L-Ser in Table 5. In all these crystals, the estimated enthalpies for the three $\mathrm{N}-\mathrm{H} \cdots \mathrm{X}$ $(\mathrm{X}=\mathrm{O}$ or $\mathrm{Cl}$ ) hydrogen bonds are similar. In contrast, the energies of the $\mathrm{O}-\mathrm{H}_{\mathrm{A}} \cdots \mathrm{X}$ hydrogen bonds differ very much in the three crystals. These results clearly confirm that the hydroxyl side-chain of serine amino acid plays a major role in defining the very different $\mathrm{H}$-bonding networks in the three crystals. This idea corroborates conclusions of our previous studies on the structures of crystalline DL- and L-Ser. ${ }^{4,5}$

\section{Conclusion}

Crystals of DL-Ser $\cdot \mathrm{HCl}$ were obtained, and their structure was solved by X-ray technique. This structural information was then used in the interpretation of the vibrational spectra of the substance measured in a wide range of temperatures $(300-10 \mathrm{~K})$. Spectra of isotopically doped DL-Ser $\cdot \mathrm{HCl}$, obtained in the same range of temperatures, were also investigated and allowed for the identification of bands associated with individual (uncoupled) proton-related vibrational modes in the studied crystals, which exhibit a complex H-bonding network. From these data, the enthalpies of different $\mathrm{H}$-bonds were estimated using well-known empirical correlations between the observed frequency red shifts of the stretching modes $\left(v_{1}\right)$ and blue shifts of the out-of-plane bending modes $\left(v_{4}\right)$ upon H-bond formation and the corresponding $\mathrm{H}$-bond enthalpies. A systematic comparison between the results obtained in the present study with those of our previous studies ${ }^{4,5}$ on DL- and L-Ser crystals revealed that the vibrational spectra of the three crystals reflect well the different characteristics of their H-bond networks and, in particular, doubtlessly confirm that the hydroxyl side-chain of serine amino acid plays a major role in defining the very different $\mathrm{H}$-bonding networks in these three crystals.

As a complement to the experimental studies undertaken for crystalline DL-Ser $\cdot \mathrm{HCl}, \mathrm{DFT}(\mathrm{B} 3 \mathrm{LYP}) / 6-311++\mathrm{G}(\mathrm{d}, \mathrm{p})$ theoretical calculations of the vibrational spectra of the isolated cation of DL-Ser were also carried out, providing further support to the interpretation of the experimental data.

Acknowledgment. This work was financially supported by "Fundação para a Ciência e a Tecnologia", Lisbon (Research Projects POCI/QUI/59019/2004 and POCI/QUI/58937/2004, and Grant SFRH/BPD/22410/2005).

Supporting Information Available: Additional details regarding the structural parameters of the title compound and 13 of its conformers. This material is available free of charge via the Internet at http://pubs.acs.org.

\section{References and Notes}

(1) Stepanian, S. G.; Reva, I. D.; Radchenko, E. D.; Rosado, M. T. S.; Duarte, M.; Fausto, R.; Adamowicz, L. J. Phvs. Chem. A 1998, 102, 1041.

(2) (a) Jarmelo, S.; Lapinski, L.; Nowak, M. J.; Carey, P. R.; Fausto, R. J. Phvs. Chem. A 2005, 109, 5689. (b) Jarmelo, S.; Fausto, R. J. Mol. Struct. 2006, 786, 175.

(3) (a) Pauling, L. In Química Geral, 2nd ed.; Ao Livro Técnico S.A.: Rio de Janeiro, 1967; p 649. (b) Wyman, J. J. J. Am. Chem. Soc. 1934, 56, 536. (c) Wyman, J. J. Chem. Rev. 1936, 19, 213.

(4) Jarmelo, S.; Reva, I.; Rozenberg, M.; Carey, P. R.; Fausto, R. Vib. Spectrosc. 2006, 41, 73 
(5) Jarmelo, S.; Reva, I.; Carey, P. R.; Fausto, R. Vib. Spectrosc. 2007, 43,395

(6) Max, J. J.; Chapados, C. Appl. Spectrosc. 1998, 52, 963.

(7) (a) Rozenberg, M.; Loewenschuss, A.; Marcus, Y. Phvs. Chem. Chem. Phys. 2000, 2, 2699. (b) Rozenberg, M.; Jung, C.; Shoham, G. Phys. Chem. Chem. Phys. 2003, 5, 1533.

(8) (a) Rozenberg, M.; Shoham, G.; Reva, I.; Fausto, R. Spectrochim. Acta, Part A: Mol. Biomol. Spectrosc. 2003, 59, 3253. (b) Rozenberg, M.; Shoham, G.; Reva, I.; Fausto, R. Phys. Chem. Chem. Phys. 2005, 7, 2376.

(9) Rozenberg, M.; Shoham, G.; Reva, I.; Fausto, R. Spectrochim. Acta. Part A: Mol. Biomol. Spectrosc. 2004, 60, 463.

(10) Rozenberg, M.; Shoham, G.; Reva, I.; Fausto, R. Spectrochim. Acta. Part A: Mol. Biomol. Spectrosc. 2004, 60, 2323.

(11) Rozenberg, M.; Jung, C.; Shoham, G. Spectrochim. Acta, Part A: Mol. Biomol. Spectrosc. 2005, 61, 733.

(12) (a) Rozenberg, M.; Jung, C.; Shoham, G. Spectrochim. Acta, Part A: Mol. Biomol. Spectrosc. 2004, 60, 2369. (b) Rozenberg, M.; Shoham, G.; Reva, I.; Fausto, R. Spectrochim. Acta, Part A: Mol. Biomol. Spectrosc. $\mathbf{2 0 0 5}, 62,233$

(13) Rozenberg, M.; Loewenschuss, A.; Lutz, H. D.; Marcus, Y. Carbohydr. Res. 1999, 315, 89.

(14) Rozenberg, M.; Loewenschuss, A.; Marcus, Y. Carbohvdr. Res. 2000, 328, 307.

(15) Chakraborty, D.; Manogaran, S. Journal of Molecular StructureTheochem 1998, 422, 13.

(16) Noguera, M.; Rodriguez-Santiago, L.; Sodupe, M.; Bertran, J. J. Mol. Struct. (THEOCHEM) 2001, 537, 307.

(17) Chang, G.; Guida, W. C.; Still, W. C. J. Am. Chem. Soc. 1989, $111,4379$.

(18) Frisch, M. J.; Trucks, G. W.; Schlegel, H. B.; Scuseria, G. E.; Robb, M. A.; Cheeseman, J. R.; Zakrzewski, V. G.; Montgomery, J. A., Jr.; Stratmann, R. E.; Burant, J. C.; Dapprich, S.; Millam, J. M.; Daniels, A. D.; Kudin, K. N.; Strain, M. C.; Farkas, O.; Tomasi, J.; Barone, V.; Cossi, M.; Cammi, R.; Mennucci, B.; Pomelli, C.; Adamo, C.; Clifford, S.; Ochterski, J.; Petersson, G. A.; Ayala, P. Y.; Cui, Q.; Morokuma, K.; Salvador, P.; Dannenberg, J. J.; Malick, D. K.; Rabuck, A. D.; Raghavachari, K.; Foresman, J. B.; Cioslowski, J.; Ortiz, J. V.; Baboul, A. G.; Stefanov, B. B.;
Liu, G.; Liashenko, A.; Piskorz, P.; Komaromi, I.; Gomperts, R.; Martin, R. L.; Fox, D. J.; Keith, T.; Al-Laham, M. A.; Peng, C. Y.; Nanayakkara, A.; Challacombe, M.; Gill, P. M. W.; Johnson, B.; Chen, W.; Wong, M. W.; Andres, J. L.; Gonzalez, C.; Head-Gordon, M.; Replogle, E. S.; Pople, J. A. Gaussian 98, revision A.11.1; Gaussian, Inc.: Pittsburgh PA, 2001.

(19) McLean, A. D.; Chandler, G. S. J. Chem. Phvs. 1980, 72, 5639.

(20) Becke, A. D. Phys. Rev. A 1988, 38, 3098.

(21) Lee, C. T.; Yang, W. T.; Parr, R. G. Phvs. Rev. B 1988, 37, 785.

(22) (a) Barone, V.; Adamo, C. J. Chem. Phys. 1996, 105, 11007. (b)

Frisch, M. J.; Pople, J. A.; Binkley, J. S. J. Chem. Phvs. 1984, 80, 3265.

(23) Iogansen, A. V.; Rozenberg, M. S. J. Appl. Spectrosc. (U.S.S.R.) 1968, 9, 1027.

(24) Boldyreva, E. V.; Kolesnik, E. N.; Drebushchak, T. N.; Sowa, H.; Ahsbahs, H.; Seryotkin, Y. V. Z. Kristallogr. 2006, 221, 150.

(25) Boldyreva, E. V.; Kolesnik, E. N.; Drebushchak, T. N.; Ahsbahs, H.; Beukes, J. A.; Weber, H. P. Z. Kristallogr. 2005, 220, 58.

(26) Rosado, M. T.; Duarte, M.; Fausto, R. Vib. Spectrosc. 1998, 16, 35.

(27) (a) Rozenberg, M. S.; Iogansen, A. V. Opt. Spektrosk. 1988, 64, 693. (b) Iogansen, A. V. Izv. Akad. Nauk. SSSR Ser. Fiz. 1989, 53, 1741. (c) Iogansen, A. V.; Rozenberg, M. S. J. Struct. Chem. 1989, 30, 76.

(28) Frey, M. N.; Lehmann, M. S.; Koetzle, T. F.; Hamilton, W. C. Acta Crystallogr., Sect. B: Struct. Sci. 1973, B 29, 876.

(29) The same reasoning applies for the non-observation of the band due to the stretching vibration of hydroxyl (acid) group in the deuterated samples.

(30) Rozenberg, M. S. Spectrochim. Acta, Part A: Mol. Biomol. Spectrosc. 1996, 52, 1559.

(31) (a) Rosado, M. T. S. Estrutura Molecular e Espectros Vibracionais de n- e Alfa-Aminoácidos Simples. Ph.D. Thesis, University of Lisbon, 2004. (b) Fischer, G.; Cao, X. L.; Cox, N.; Francis, M. Chem. Phvs. 2005, 313, 39. (c) Stepanian, S. G.; Reva, I. D.; Radchenko, E. D.; Adamowicz, L. J. Phvs. Chem. A 1999, 103, 4404.

(32) Iogansen, A. V. Spectrochim. Acta, Part A: Mol. Biomol. Spectrosc. 1999, $55,1585$.

JP7115609 